\title{
Evaluation of soil salinity level through using Landsat-8 OLI in Central Fergana valley, Uzbekistan
}

\author{
Ilhomjon Aslanov ${ }^{1, *}$, Shovkat Kholdorov ${ }^{2}$, Shodiqul Ochilov ${ }^{3}$, Azamat Jumanov ${ }^{1}$, Zafarjon \\ Jabbarov $^{3}$, Ilyakhoja Jumaniyazov ${ }^{1}$, and Normamat Namozov ${ }^{4}$ \\ ${ }^{1}$ Tashkent Institute of Irrigation and Agricultural Mechanization Engineers, Tashkent, Uzbekistan \\ 2 "Soil composition and Repository, Quality analysis centre" The State Unitary Enterprise (SCRQAC \\ SUE), Tashkent, Uzbekistan \\ ${ }^{3}$ National University of Uzbekistan Named after Mirzo Ulugbek, Tashkent, Uzbekistan \\ ${ }^{4}$ Tashkent State Agrarian University, University str., 2, Tashkent province, Uzbekistan
}

\begin{abstract}
Soil salinity is a major concern in the Uzbekistan. Fergana valleys agricultural lands, it negatively affects plant growth, crop yields, whereas in central part of the valley is semi-desert and desert affects agricultural areas due to subsidence, corrosion and ground water quality, leading to further soil erosion and land degradation. Traditional soil salinity assessments have been doing by collecting of soil samples and laboratory analyzing of collected samples for determining totally dissolved soils (TDS) and electro conductivity, but, Geo-informatic systems (GIS) and Remote Sensing (RS) technologies provides more efficient, economic and rapid tools and techniques for soil salinity assessment and soil salinity mapping. Main goals of this research are to map soil salinity of Fergana valley, to show relation of its result with traditional analysing and analysing withGIS technology As a source of satellite images has been used Landsat-8 OLI . Research areas every arable land validity point of different locations were measured by Traditional soil salinity assessments by Soil composition and Repository, Quality analysis center was compared to our research conducted on satellite sensor and it can be said that the study have done correctly.
\end{abstract}

\section{Introduction}

Soil salinity is being studied world-wide using various techniques with satellite observations and remote sensing is the most significant of them for being cost effective, time saving and provides global coverage [1-5]. Diverse types of satellite data are being used in various kinds of soil salinity studies with similar approaches. RS and GIS related approaches have been adopted by numerous published works in attempts to study, map and model soil salinity in an effectively efficient way $[6-9,16]$.

\footnotetext{
*Corresponding author: $\underline{\text { ilhomaslanov@tiiame.uz, } \text { ilhomaslanov@gmail.com }}$
} 
In particular, one of the urgent tasks today is to ensure effective use of existing irrigated lands, preserve, restore and improve soil fertility and ensure their targeted use. The decree of the First President of the Republic of Uzbekistan on April 13, 2013 No. PD-1958 "On measures to further improve the meliorative status of irrigated lands and rational reasonable of water resources for 2013-2017" and the implementation of this resolution on February 24, 2020 Cabinet of Ministers No. 39 concerning "On the territory Republic" of the State Committee for Land Resources, Geodesy of Irrigated Agricultural Land, a study is being conducted on soil maps [13]. Traditional soil salinity assessments have been doing by collecting soil samples and laboratory analysis of collected samples for determining TDS and electro conductivity $[4,11]$. However, traditional methods of soil salinity assessment are slow and expensive, because sampling requires long time activities [10, 14]. The time consummation of traditional methods has been stated by [12,18], but GIS and Remote Sensing technologies provide more efficient, economic and rapid tools and techniques for soil salinity assessment and soil salinity mapping. As well as, in Uzbekistan the research institutes and projects, which are responsible for soil salinity assessment using GIS tools in high level. Current, two main organizations are doing soil salinity assessment in the study area. They are Soil composition and Repository, Quality analysis center" The State Unitary Company and Hydrologic meliorative expedition of Central Fergana valley. Both organizations are using GIS tools only for mapping and visualization of data. The methodology for soil salinity assessment has been developed by State Scientific Research Institute of Soil Science and Agrochemistry. SSRISSAC is the main research institute for soil surveys in the Republic of Uzbekistan $[11,15]$.

Syrdarya river is main water arteria of Fergana valley and flows in center of valley and is a constant passage of soil structure and ground water of valley. Soil will be influence ground water movement $[9,17]$. The proximity of the salty groundwater to the surface of the soil and the intrusion of due to diminishing river Sirdaya flows and uncertain this study was thus conducted using field data to assess the gravity of the problem. The spatial distribution of soil salinity in the IRD will provide an insight to policymakers, farmers, and agriculturists for ecological degradation prevention and restoration of the delta. Nowadays, researchers studying are developing advanced methods for soil salinity assessment, which includes GIS and RS technologies [19-21]. Main goals of this research are to map soil salinity of Central Fergana valley, to show the relation of its result with soil salinity and validity degrees' values of this field.

\section{Study area}

The study area is located in Fergana valley eastern part of Uzbekistan. Study aria located in the latitudes $40^{\circ} 58^{\prime} 06^{\prime \prime}$ 'to $41^{\circ} 05^{\prime} 47^{\prime \prime}$ ' $\mathrm{N}$ and longitudes $67^{\circ} 52^{\prime} 36^{\prime \prime}$ to $68^{\circ} 04^{\prime} 44^{\prime \prime}$ 'E. the area is 740 square kilometres (Fig. 1). According to reports of "Soil composition and Repository, Quality analysis centre" The State Unitary Enterprise $76 \%$ of lands are affected by different salinity degrees. 


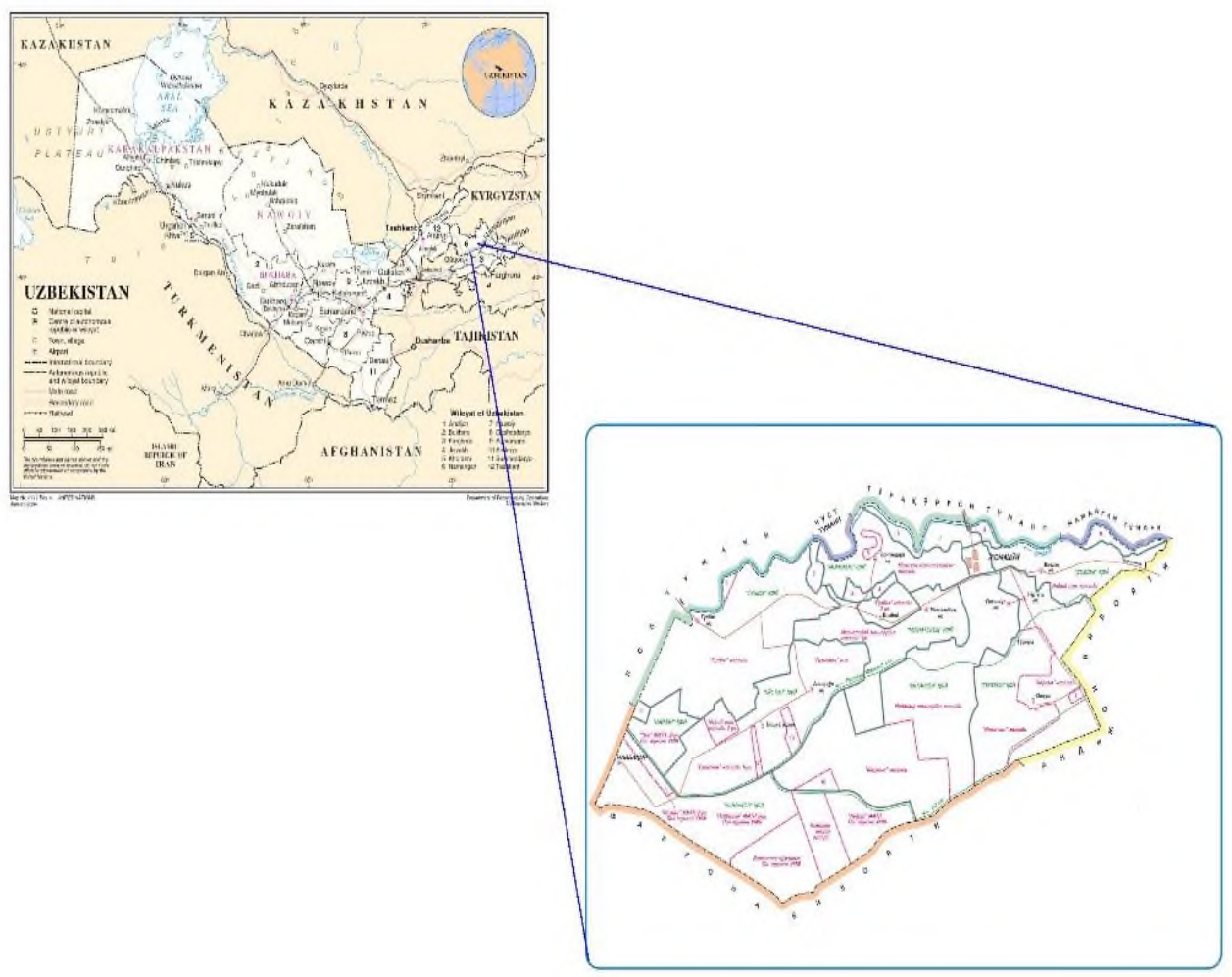

Fig. 1. Location of research area (Source: GRID-Arendal).

\section{Data}

Soil salinity and validity degrees' values are a comparative estimate of the level of soil quality and natural productivity at the average level of agricultural cultivation. Soil bartering plays an important role in the elaboration of normative assessment of the lands of agricultural commodity producers, allocation of land for farmers, the establishment of a single land tax, prevention of unauthorized allocation of cultivated land for non-agricultural purposes, land use and organization of rational reasonable of land. Soil salinity and validity degrees' values (Table 1), based on the requirements of cotton sampling, also reflect the quality of irrigated soils cultivated by all other crops in the cotton-growing complex [22, 23]. The soil salinity and validity degrees' value data and map of 2020 year were digitized and transferred using GIS software format and investigated the soil salinity values score (Fig. 2). 
Table 1. Soil salinity of arable land in research area in 2020 (Source: SCRQAC SUE).

\begin{tabular}{|c|c|c|c|c|c|c|}
\hline & $\begin{array}{c}\text { All arable } \\
\text { lands }\end{array}$ & $\begin{array}{c}\text { Very low } \\
\text { salinity }\end{array}$ & $\begin{array}{c}\text { Low } \\
\text { salinity }\end{array}$ & $\begin{array}{c}\text { Medium } \\
\text { salinity }\end{array}$ & $\begin{array}{c}\text { High } \\
\text { salinity }\end{array}$ & $\begin{array}{c}\text { Very high } \\
\text { salinity }\end{array}$ \\
\hline $\begin{array}{c}\text { Area } \\
\text { (ha) }\end{array}$ & 34753 & 8210,1 & 10785 & $13673 ? 7$ & 1171,2 & 913 \\
\hline Area \% & 100 & 23,6 & 31 & 39.3 & 3,4 & 2,6 \\
\hline
\end{tabular}

Based on the paper versions of maps has created attributive table of the digital maps, which is describing few parameters of polygons. Attributive table consists of information about Soil salinity level of polygons, their soil type.

\subsection{Satellite data}

The satellite images of research area (Path 154, Row 32) for 2020 years have been downloaded from open sources (earthexplorer.usgs.gov). As a source of satellite images has been used Landsat OLI 8 Earth-observation satellite, which launched on October 16, 2020 (salinity level of arable land peaks after vegetation period in the second half of October and the beginning of November). Once every 16 days the satellite is capturing image by high spectral sensors the entire worldview. The spatial resolution of images is 30 meters, which means one pixel of the image is $30 \times 30$ meter of ground view (U.S. Geological Survey, 2020).

\section{Methods}

First of all, remotely sensed Landsat 8 OLI image was projected to the WGS 1984 UTM Zone $42 \mathrm{~N}$ coordinate system and clipped to the extent of the study area. After that, we used an NDSI mask to extract the saline areas. Normalized Difference Soil Index (NDSI) using equation formula can be used only for Landsat OLI 8 satellite sensor raster layers were calculated using the following formula (Equation 1) [3]:

$$
\mathrm{NDSI}=(\text { Green }-\mathrm{SWIR}) /(\text { Green }+ \text { SWIR }) .
$$

The range of NDSI values was divided into 5 classes (Table 2), linked to the soil salinity classification (no salinization, weak, moderate, severe, and very severe salinization) $[15,23]$.

For the analysing of soil type was used the Soil Adjusted Vegetation Index (SAVI) from a multiband raster Landsat 8 OLI object and returns a raster object with the index values. The Soil-Adjusted Vegetation Index (SAVI) is a vegetation index that attempts to minimize soil brightness influences using a soil-brightness correction factor. This is often used in arid and semi arid regions where vegetative cover is low soil salinity soils high [23]:

$$
\mathrm{SAVI}=((\mathrm{NIR}-\mathrm{Red}) /(\mathrm{NIR}+\mathrm{Red}+\mathrm{L})) *(1+\mathrm{L}),
$$

there: L- 0.5 (The amount of green vegetation cover).

Table 2. NDSI range on soil salinity classes.

\begin{tabular}{|c|c|}
\hline NDSI range & Soil salinity level \\
\hline $0.15-0.25$ & Very high salinization \\
\hline $0.26-0.40$ & High salinization \\
\hline $0.41-0.55$ & Medium salinization \\
\hline $0.56-0.70$ & Low salinization \\
\hline $0.71-1.00$ & Very low salinization \\
\hline
\end{tabular}


In this case, atmospheric and radiometric correction are not in demand, because, Landsat OLI 8 sensor does these corrections itself during capuring remotely images. For identify how saline soils spectral reflectance differs from low saline soils, it was necessary to plot the spectral reflectance of various levels of soil salinities. This is believed to aid in the process of developing a soil salinity index particularly suited for desert soils.

\section{Results}

In research area soil salinity caused by natural or human-induced processes is a major environmental hazard. Crop growth reduction due to salinity is generally related to the land use and land type. High soil salinity can also cause ineffective use lands, result in the accumulation of aglomelarative works on lands. In many areas of the world, soil salinity is the factor limiting agricultural lands. We have analysed and implemented Normalized Difference Soil Index to achieve our goal and as a consequence, it can be detected that arable land without salt content is partially not exist in soil salinity map (Fig. 2).

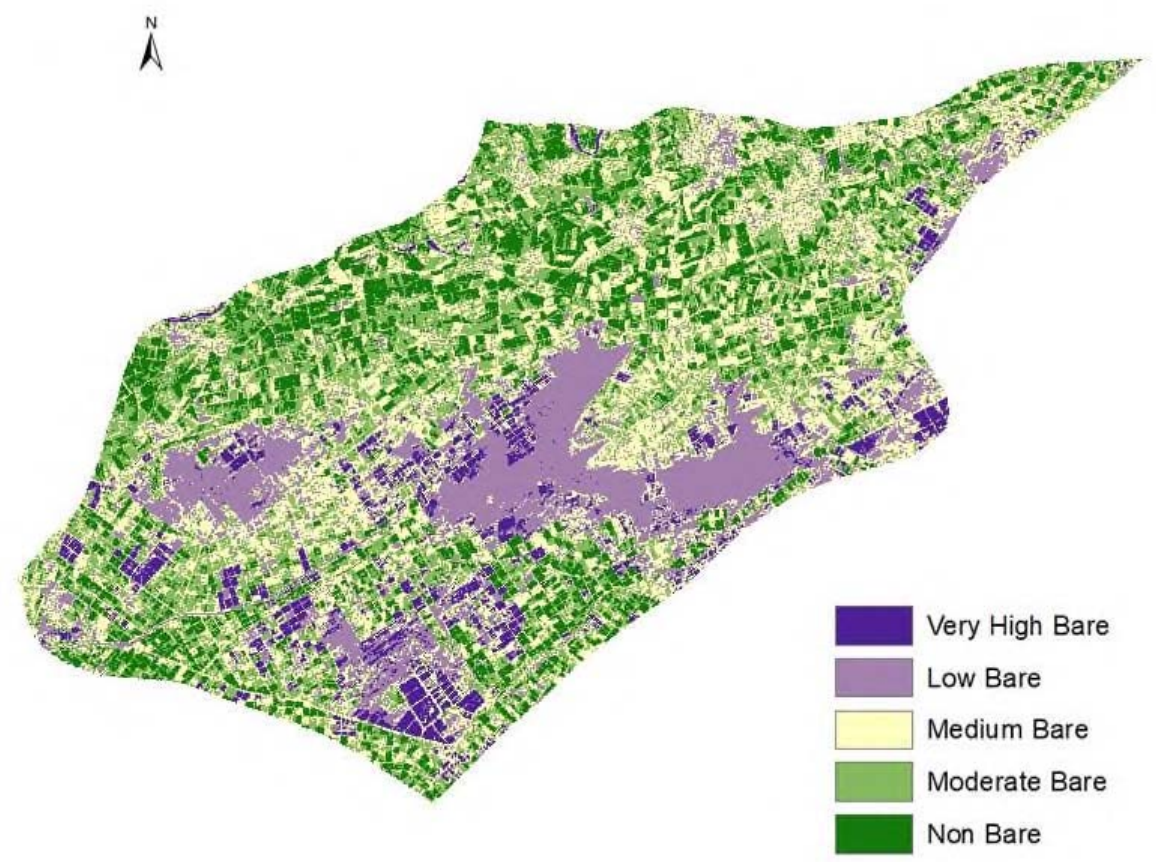

Fig 1. Illustration of soil types on the study area.

The salinity map above exhibits itself that moderate and severe salt affected soils were predominant in Syrdarya province, exept from the northern part. However, it can be met very high concentration of salt contents on topsoil in the central and western-central territory of the province in 2020. below:

The statistical analysis of area changes for diverse soil salinity level indicated in Table 3 
Table 3. Changes of area (measured by percentages of total arable land area) for salinity level of soil.

\begin{tabular}{|c|c|c|c|c|}
\hline \multicolumn{5}{|c|}{ Salinity level of topsoil } \\
\hline $\begin{array}{c}\text { Very } \\
\text { severe }\end{array}$ & Severe & Moderate & Weak & No salinization \\
\hline 9,36 & 26,17 & 50,48 & 11,23 & 2.76 \\
\hline
\end{tabular}

According to Fig. 3 illustrating soil salinity values of different research area, every arable land validity point of different locations were measured by State Commite of the Republic of Uzbekistan of Land Resources, Geodesy, Cartography and State Cadastre (SCRULRGCSC) was compared to our research conducted on satellite sensor and it can be said that the study have done correctly.

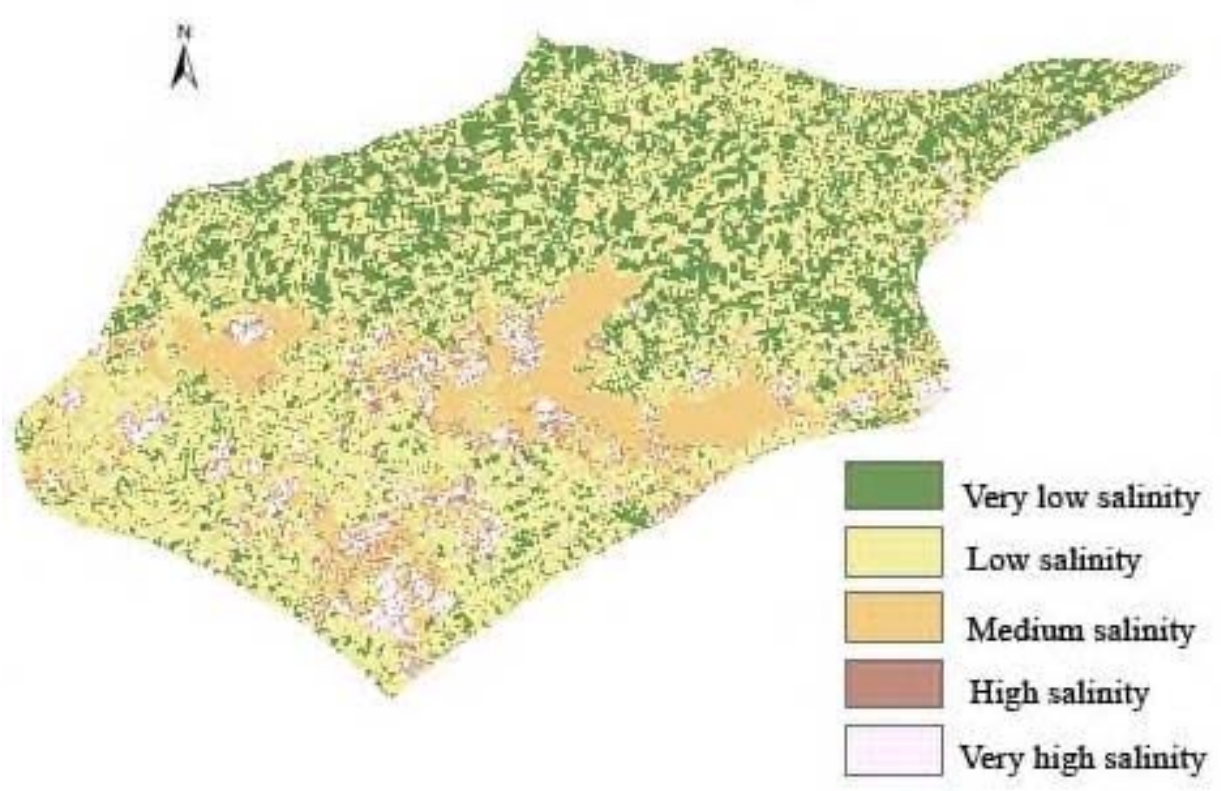

Fig 3. Illustration of soil salinity on the study area.

The results of the NDSI analysis show that the analysis of the soils of the area study with the help of remote sensing technology is reflected in the statistics and can be applied (Table 3). In soil mapping from remotely sensed data, the term accuracy is typically used to express the degree of 'correctness' of classification. Map that is derived from a remote sensing classification process should provide a high measure of its ac curacy. Classification accuracy refers to the degree to which a map derived from a remote sensing classification process matches real feld information.

\subsection{Discussion}

Platonov et al [4] gave recommendations to decrease cost of mapping of soil salinization. To use the multi-temporal satellite images for creation of soil salinity map and to collect the soil samples from limited amount of points inside the fields with different gradation of soil salinity from soil salinity map were indicated and it was mentioned that use of this approach will increase the accuracy of soil salinity map with minimum expenditures on soil sampling [5, 15-20]. 
Akramkhanov et al [1] mentioned on the research that significant correlations between quantifiable terrain attributes and soil salinity exist. Such a relationship was successfully used to estimate soil salinity at farm scale solely based on quantified environmental variables. Therefore, the environmental variables must be available for the study area in high resolution or easily measurable [1, 10-14].

\section{Conclusion}

Soil sampling is a costly, time and labor consuming activity with the average norm for soil sampling being 15-20 points per day by one soil specialist and two workers. So, the satellite remotely sensed images are freely available now from Internet, and owing to our study, through satellite sensors, level of land degradation as an example of soil salinization can be measured $80 \%$ correctly. Consequently, using GIS and RS for soil salinity mapping is extremely cost-effective with a higher degree of spatial accuracy. Our results displayed almost all of arable land territories are mostly in danger by different types of salinity level. As far as there is not taken proper and prompt measures in this field, it will negatively reflects to our economy and agriculture.

Funding for this study provided by the project entitled "Creating geo-information base for salinity land for agricultural lands" (2021-2023), funded by the Ministry of innovative development of the Republic of Uzbekistan.

\section{References}

1. A. Akramkhanov, P. L. Vlek, Environ. Monit. Assess., 184(4), 2-17 (2012)

2. A. Allbed, L. Kumar, Advances in Remote Sensing, 2(04), 69958 (2013)

3. T. K. Ghabour, L. Daels, Egypt. J. Soil. Sci., 33(4), 69-74 (1993)

4. A. Platonov, A. Noble, R. Kuziev, Developments in Soil Salinity Assessment and Reclamation, 635 (Springer, 2013)

5. R. A. Kulmatov, S. A. Adilov, S. Khasanov, IOP Conf. Ser.: Earth Environ. Sci., 614(1), 012149 (2020)

6. A. Jumanov, S. Khasanov, A. Tabayev, G. Goziev, U. Uzbekov, E. Malikov, IOP Conf. Ser.: Earth Environ. Sci., 614(1), 012150 (2020)

7. S. Isaev, S. Khasanov, Y. Ashirov, T. Karabaeva, A. Gofirov, E3S Web Conf., 244, 02012 (2021)

8. Y. Peng, F. Li, N. Xu, R. Kulmatov, K. Gao, G. Wang, Y. Zhang, Y. Qiao, Y. Li, H. Yang, S. Hao, Q. Li, S. Khasanov, Chinese Journal of Eco-Agriculture, 29(2), 312-324 (2021)

9. S. Isaev, S. Khasanov, Y. Ashirov, A. Gofirov, T. Karabaeva, E3S Web Conf., 244, 02047 (2021)

10. R. Kulmatov, A. Taylakov, S. Khasanov, Environ. Sci. Pollut. Res., 28(10), 12245-12255 (2021)

11. S. K. Isaev, R. U. Rakhmonov, S. S. Tadjiev, G. I. Goziev, S. Z. Khasanov, IOP Conf. Ser.: Earth Environ. Sci., 614(1), 012147 (2020)

12. M. Lehoczky, Z. Abdurakhmonov, E3S Web Conf., 227, 04001 (2021)

13. B. Alikhanov, S. Alikhanova, R. Oymatov, Z. Fayzullaev, A. Pulatov, IOP Conf. Ser.: Mater. Sci. Eng., 883(1), 012088 (2020) 
14. A. Bannari, N. Hameid Mohamed Musa, A. Abuelgasim, A. El-Battay, Appl. Earth Obs. Remote Sens., 13, 95-120 (2020)

15. K. A. Nguyen, Y. A. Liou, H. P. Tran, P. P. Hoang, T. H. Nguyen, Prog. Earth Planet. Sci., 7 (2020)

16. A. A. A. Maliki, A. Chabuk, M. A. Sultan, B. M. Hashim, H. M. Hussain, N. AlAnsari, Air. Soil Pollut., 231, 15-25 (2020)

17. S. Meti, Hanumesh, P. D. Lakshmi, M. S. Nagaraja, V. Shreepad, Int. Arch. Photogramm. Remote Sens. Spat. Inf. Sci. - ISPRS Arch, 42, 25987 (2019)

18. Z. Mamatkulov, E. Safarov, R. Oymatov, I. Abdurahmanov, M. Rajapbaev, E3S Web Conf., 227, 03001 (2021)

19. S. Rakhmonov, U. Umurzakov, K. Rakhmonov, I. Bozarov, O. Karamatov, E3S Web Conf., 227, 01002 (2021)

20. I. Musaev, A. Bokiev, M. Botirova, E3S Web Conf., 227, 05004 (2021)

21. O. Ruzikulova, N. Sabitova, G. Kholdorova, E3S Web Conf., 227, 03004 (2021)

22. I. Aslanov, S. Khasanov, Y. Khudaybergenov, M. Groll, Ch. Opp, F. Li, E. Ramirez Del-Valle, E3S Web Conf., 227, 02005 (2021)

23. N. Sabitova, O. Ruzikulova, I. Aslanov, E3S Web Conf., 227, 03003 (2021) 